\title{
Critical Issues for Psychiatric Medication Shared Decision Making With Youth and Families
}

\author{
Megan S. O'Brien, Elizabeth L. Crickard, Charles A. Rapp, Cheryl L. Holmes, \& Thomas P. McDonald
}

\begin{abstract}
The primary aims of this article are to describe the current context for youth shared decision making (SDM) within the U.S. children's mental health system and to identify important considerations for the development of this approach as a research and service domain. The notion is substantiated in the literature that participation in treatment decisions can prepare youth for making their own decisions as adults, can be therapeutic, and can have positive effects on their self-confidence and self-esteem. Still, the complex youth-family-provider dynamic raises important issues that need to be addressed before SDM can be successfully implemented.
\end{abstract}

\section{IMPLICATIONS FOR PRACTICE}

- $\quad$ Developing a youth SDM model will involve practitioner training, training for youth and parents, defining roles for youth and parents, consent, confidentiality, service delivery factors, and identifying outcomes.

0 hared decision making (SDM) is a growing tradition in the management of chronic illnesses, whereby medical decisions result from collaborative consultation between the patient and his or her caregivers and physicians. This is in contrast to conventional approaches, which can range from complete deference to the provider-with no input from the patient or the patient's caregivers-to placing the majority of the responsibility with the client via "informed choice." In this latter approach, practitioners lay out all of the options and the client makes a choice, independent of the practitioner's guidance (Charles, Whelan, Gafni, Willan, \& Farrell, 2003).

Until recently, SDM approaches have focused on decisions related to physical ailments such as asthma, breast and prostate cancer, diabetes, or cardiac rehabilitation (Butz, Walker, Pulsifer, \& Winkelstein, 2007; Corser, Holmes-Rovner, Lein, \& Gossain, 2007; Volk, Cass, \& Spann, 1999; Williams, Jones, Elwyn, \& Edwards, 2008). Only in the past few years has SDM received attention and acceptance as a necessary component of adult behavioral health care (Adams \& Drake, 2006; Deegan \& Drake, 2006; Deegan, Rapp, Holter, \& Riefer, 2008). Acceptance of SDM as an approach for youth consumers of mental health services and their families has been relatively slow to follow suit (dosReis \& Myers, 2008) despite acceptance for use with decisions about physical ailments similar to that documented with adults. Participation in general acute care pediatric units and shared decisions about treatment plans for chronic conditions such as asthma and diabetes suggest that youth want to be involved in decisions about treatment (Coyne, 2006; Kelsey, Abelson-Mitchell, \& Skirton, 2007); have the capacity for involvement in decisions about treatment (Alderson, Sutcliffe, \& Curtis, 2006); need support and encouragement to participate fully in SDM (Butz et al.); and can be more engaged in decision making if decision tools, such as visual aids and role modeling, are used (Butz et al.).

However, studies indicate that SDM, while valued as a primary tenet of ideal patient-practitioner communication, is likely not carried out in practice (S. Ford, Schofield, \& Hope, 2006; Karnieli-Miller \& Eisikovits, 2009; Seale, Chaplin, Lelliott, \& Quirk, 2006). The oppor- tunity to avoid similar discordance or mere "lip service" in the development of a youth and family SDM model for psychotropic medication prompted the need for the current article. In other words, rather than simply promoting the value of collaborative decision making, what is needed is a detailed process by which youth and families can be engaged (Baston, 2008). Without this specific attention, it is likely that the practitioner will resort to traditional authoritarian approaches, which can bypass the challenges of a collaborative dialogue with a youth and his or her caregiver. Moreover, the added complexity of youth and parent or caregiver involvement in medical decisions-as opposed to the direct, one-on-one relationship between an adult patient and provider-necessitates focus on a youth-parent-provider model in its own right.

Thus, the primary aims of this article are to describe the current context for youth SDM within the U.S. children's mental health system and describe practical issues to consider in seeking to develop or enhance an SDM process between youth (ages approximately 14 to 17 years) and families navigating choices related to psychiatric medications.

\section{Current Context: U.S. Children's Mental Health System}

Deinstitutionalization, the advent of managed care, and the emergence of the consumer and survivor movements significantly changed the landscape of community mental health services, beginning with increased involvement of adult consumers (Mechanic, 1999). As such, SDM with adult mental health consumers is inextricably linked to adult consumer movements, which have fought in the last quarter century against the traditional medical model, which holds that persons with mental illness are unable to make decisions about their own health care. It has only been in the past 10 years that we began the shift from a provider-driven service delivery system in which youth and family members were regarded as somewhat passive recipients of provider instructions, to a more family-driven system in which youth and parents partner with providers in all aspects of care, including decision making, service delivery, and accountability (Osher, Quinn, \& Hanley, 2002; Osher, Koyanagi, Pires, McCarthy, \& Webman, 1997; Osher, 1998).

There is now a growing trend toward youth involvement in mental health systems of care, policymaking, and advocacy (Materese, Mc- 
Ginnis, \& Mora, 2005; Osher \& Osher, 2002). ${ }^{1}$ Evidence suggests that youth involvement in mental health systems of care leads to positive outcomes, including increased self-confidence, improved behavior and leadership skills, and improved programs designed to support youth (Gyamfi, Keens-Douglas, \& Medin, 2007). Despite this recognition, youth involvement initiatives have primarily related to decisions that affect services at system or organizational levels. In comparison, SDM involves making decisions about individual medical treatment options.

\section{What Is Shared Decision Making With Youth?}

Empowerment through partnership. Part advocacy, part clinical intervention, empowerment of youth and caregivers is a natural outcome of a SDM process. Both parties are actively involved in determining the best course of treatment, and treatment decisions are based on agreement from both parties (Charles, Gafni, \& Whelan, 1997). Unlike the traditional model, in which practitioners prescribe and make all treatment decisions, SDM is based on a relationship-centered approach (Elwyn, Edwards, Kinnersley, \& Grol, 2000; Epstein, Alper, \& Quill, 2004). As such, it depends on good communication and the development of a trusting relationship between the client and practitioner (Adams \& Drake, 2006; Elwyn et al., 2000; Schauer, Everett, del Vecchio, \& Anderson, 2007).

The goal of traditional models is often to increase a client's conformity to the practitioner's ideas about best treatment options (Deegan \& Drake, 2006). SDM, on the other hand, empowers clients by assuming that both the client and practitioner are experts who can share information and collaborate throughout the treatment process (Deegan \& Drake, 2006; Perlman \& Dougherty, n.d.). Promoting this empowerment also requires the acknowledgment of a client's right to be involved in decisions about his or her health and treatment and the active encouragement of client participation in decision making by the practitioner (Fraenkel \& McGraw, 2007a, 2007b).

Empowerment through sharing information. According to the guiding principles of family-driven care, families and youth should be given accurate information to support goal-setting and decisions (Substance Abuse and Mental Health Services Administration [SAMHSA], 2008). Interviews with patients between the ages of 9 and 15 who were receiving treatment in a British pediatric unit indicated that the children wanted information to help them understand their illness. Moreover, interviewees reported that they "felt happy, reassured and treated as a person with rights" when provided with information about their care (Coyne, 2006, p. 65).

In a study concerning decisions about psychotropic medication treatment for youth, parents reported seeking information about treatment from multiple sources. Sources included other family members, school personnel, and the Internet. However, the majority of parents relied heavily on the expertise and guidance of professionals and described their child's psychiatrist as the "most reliable source of information" for medication decisions (Lambert, Friedman, Jerz, \& Hacker, 2008, p. 5). Indeed, due to the relative newness of SDM, youth and families may rely on practitioners to be responsible for treatment decisions based on traditional roles in the decision process (Edwards et al., 2006). Therefore, parents and their children must acquire both information and tools to use this information to participate in medi-

\footnotetext{
${ }^{1}$ A mental health system of care is a coordinated network of comprehensive services for children experiencing emotional and behavioral disorders and their families. According to system of care principles, mental health care for children "should be comprehensive, coordinated, community-based, individualized, culturally competent, child centered, and family focused"(Friesen, 2005, p. 6).
}

cal treatment decisions. Techniques for sharing information with youth include using visual aids, role playing, and modeling examples (Butz et al., 2007).

Empowerment through appropriate involvement. Respecting a client's right to be involved in decisions should be balanced with respect for the client's preferred level of involvement in medical decisions (Edwards \& Elwyn, 2006; Elwyn et al., 2000; Levinson, Kao, Kuby, \& Thisted, 2005). Indeed, according to Sevdalis and Harvey (2006), the "cornerstone of shared decision-making is patient preferences" (p. 245). Practitioners may be concerned about adding stress to patients by involving them in shared decisions, and patients may not desire the level of responsibility accompanying increased involvement (Edwards \& Elwyn). Although patient or client preference may vary, there is evidence that, in general, patients and clients desire some level of involvement in a decision-making process, with more patients preferring a shared versus autonomous process (Deber, Kraetschmer, Urowitz, \& Sharpe, 2007; Stacey et al., 2008; Thornton, Edwards, \& Elwyn, 2003).

\section{Youth and Family Involvement in Mental Health Decision Making}

\section{Developmental Considerations}

In adolescence, as young people shift from a family focus to greater identification with community and peers, developmental tasks become primarily social (Huffine, 2005). For youths experiencing mental illness, this process can be problematic. There is the potential for youth to become too dependent on their parents or, at the other extreme, to rebel against their parents in ways that can increase their risk for social and emotional difficulties (Huffine). Making decisions about treatment can support healthy adolescent development and prepare teens for their transition to adulthood (Huffine). Furthermore, opportunities to make decisions about mental health care can be therapeutic (Costello, 2003). However, it is important to involve families in treatment in ways that will meet an adolescent's healthy developmental needs and enhance the family's strength.

In a discussion about the involvement of children and adolescents in medical decision making, McCabe (1996) asserted that "the process needs to be respectful of both children's rights to self-determination and the integrity of families, since family friction can be more harmful than not involving the child” (p. 514). Families and caregivers are important resources for children and adolescents throughout their lives (Cooper, Rimm, \& Arensdorf, 2007). In focused interviews about their perceptions of participation in decision making, 12- to 16-yearolds in an acute care environment reported that they wanted to be included in decisions, felt alienated when their physicians spoke only to their parents, and characterized lack of communication as a key barrier to inclusion in decision making (Kelsey et al., 2007). A review of mental health literature also indicates that children and adolescents want to be involved in decisions that affect them (Dogra, 2005).

Parents and practitioners may have concerns about the developmental capacity of youth to participate in a shared decision (McCabe, 1996). However, there is evidence that children and adolescents have the capacity to participate in decisions about their own medical treatment. For example, a review of SDM in the treatment of children's diabetes indicates that children "sometimes have a much more sophisticated capacity for taking charge of their own health care decisions than is usually recognized in bioethics" (Alderson et al., 2006, p. 25). Managing chronic conditions such as diabetes involves daily deci- 
sions about lifestyle choices and taking medications. When parents are not available, such as during the school day or during social activities with peers, children still have to make decisions about managing their condition (Alderson et al.). A study of youth between the ages of 12 and 16 in an inpatient pediatric acute care unit demonstrated that participants were capable of mature decision making; youth even recognized when they lacked information or were not feeling well enough to make certain decisions about treatment (Kelsey et al., 2007). Youth have specific expertise about their bodies and lives. Empowering youth to participate in treatment decisions can ensure that this expertise informs the treatment process (Lambert et al., 2008).

\section{Preferences for Involvement}

Parents may have different preferences for levels of involvement in decision making than their children, and these preferences must be considered (Coyne, 2006). In interviews with parents of children in a general pediatric unit, some parents expressed reservations about their children's involvement in decision making. Parents were concerned that their children's competence and chronological age did not always match. Parents also shared worries about the possible emotional repercussions for children who are given the responsibility for agreeing to treatment (Coyne). Parenting style can affect the boundaries parents place on their children's autonomous decision making. However, evidence suggests that even "permissive parents," as defined in Baumrind's typology of parenting styles, are less likely to be lenient about issues related to an adolescent's health and safety (Smetana, 1995). ${ }^{2}$

Providers also need to be aware of the sociodemographic and cultural factors that may influence preferences for levels of involvement. Several studies indicate variation by age, gender, and race/ethnicity in the acceptance of psychiatric medication and trust in physicians (Pescosolido, 2007; Pescosolido et al., 2008; Sleath et al., 2010), but very few studies examine patient and provider characteristics related to preferences for involvement in health care decisions. Among adults, age appears to be negatively associated with preference for involvement (e.g., Cassileth, Zupkis, Sutton-Smith, \& March, 1980; Levinson et al., 2005; Rosen, Anell, \& Hjortsberg, 2001; Stiggelbout \& Kiebert, 1997). The relationship of other characteristics is less conclusive (Rosen et al.), although there is some evidence to suggest that more men than women (Levinson et al.; Stiggelbout \& Kiebert), and more African American and Hispanic adults than Whites (Levinson et al.) prefer to leave medical decisions up to their physicians.

\section{Continuum-Based Perspective of Involvement}

A continuum-based approach may be helpful to address these issues specific to youth and parent involvement in SDM. McCabe (1996) described the need to address varying rates of development among children. He recommends that decision making occur on a continuum of involvement ranging from (a) children and adolescents receiving information but not participating in decisions about their illness and treatment, (b) children and adolescents making decisions and setting goals with their parents through SDM, and (c) children and adolescents making autonomous decisions about treatment. A continuum of involvement would span these three major levels depending on the needs of each individual case. Butz et al. (2007) explained that although simplistic, a continuum-based approach is intended to ad-

\footnotetext{
2 Baumrind's widely used typology describes three parenting styles including: (a) authoritative, (b) authoritarian, and (c) permissive. See http://www.devpsy.org/ teaching/parent/baumrind_styles.html for a full description of each parenting style (Grobman, 2008).
}

dress the dynamic and complex interactions among practitioners, parents, and their children.

Practitioners can work with parents to assess appropriate levels of involvement in this continuum for their children. This work should include assessing the child's capacity and preference for decision making (Butz et al., 2007; Dixon-Woods, Young, \& Heney, 1999; McCabe, 1996). Still, evidence suggests that children are not traditionally socialized to participate in the medical encounter, so both practitioners and parents may need to actively encourage and verbally reinforce children's participation (McCabe; Tates, Meeuwesen, Elbers, \& Bensing, 2002). In their guidelines to help parents assist children with decisions about medication, Cooper et al. (2007) suggested that increasing decision-making autonomy may work best for older teens. Furthermore, "graduated levels of decision making" can help adolescents to develop more independence over time and practice decisionmaking skills within a safe context (Kuther, 2003, p. 352).

\section{Practical Design Considerations}

Developing a youth SDM model for mental health medication treatment will involve a number of design considerations, including practitioner training, training for youth and parents, defining roles for youth and parents, consent, confidentiality, service delivery factors, and identifying outcomes of youth SDM. Some of these topics are not new to children's mental health services. Existing solutions and models to address these issues may already be available in current children's mental health service policies and procedures. However, a way to integrate solutions for these issues within a formal structured mental health SDM model for youth is needed now.

Practitioner training. Integrating SDM into practice requires new types of skills. Thus, training for practitioners is critical to the successful implementation of SDM (Perlman \& Dougherty, n.d.; Thornton et al., 2003). Even when practitioners are open to the concept of SDM, this approach may not be intuitive to them. In a qualitative study with six family physicians, investigators found that physicians were generally positive about SDM; however, evidence that they were putting this process into practice was limited. Specifically, physicians did not always present choices in a clear manner. For example, evidence and study results on treatment options were not regularly shared with patients. Investigators also found that plans were not usually created in a manner consistent with a partnership approach (Towle, Godolphin, Grams, \& Lamarre, 2006).

Thus, a set of competencies and a framework within which to practice SDM skills are needed (Goscha, 2009; Towle \& Godolphin, 1999). These competencies include developing partnerships and defining roles, establishing consistent engagement points for reviewing and determining client preference for information, establishing roles for auxiliary supports and involvement in decisions to avoid undue burden on the patient, responding to clients' concerns and expectations, identifying and framing treatment choices, helping clients reflect on and assess the impact of decisions, negotiating decisions, and developing an action plan with the client (Goscha, 2009; Towle \& Godolphin, 1999).

Training for youth and parents. Clients also need encouragement and support for their role in the decision-making process. Traditionally, clients have relied on practitioners as a trusted source for information and may have concerns about transitioning to a more active role in the decision-making process (Edwards \& Elwyn, 2006; Lambert et al., 2008). Interviews with participants of an SDM process for children with cerebral palsy suggest that parents and children relied 
on the expertise of their physiotherapists for decision making (Young, Moffett, Jackson, \& McNulty, 2006). In another study, children were asked about their knowledge of various diagnostic procedures they had undergone and their perceptions of involvement in decisions related to them. Investigators found that, overall, participants and their parents were not well informed, and even though they participated in discussions, their views were not often taken into account in decisions affecting them (Runeson, Martenson, \& Enskar, 2007). Youth and family members may also have unrealistic expectations for treatment, such as desiring a complete cure or symptom elimination in cases where this may not be possible. In the case of mental illness, there may also be stigma associated with psychiatric disorders (Murray-Swank, Dixon, \& Stewart, 2007). SDM competencies for youth and their parents include abilities to define their preferred role in the decision-making process; establish a partnership with practitioners; communicate their health problems, concerns, and expectations with practitioners; evaluate information; and negotiate decisions with practitioners (Towle \& Godolphin, 1999).

Defining roles for youth and parents. In a study concerning decisions about psychotropic medication, parents and youth indicated that in order to ensure an effective exchange of information with practitioners, roles for parents and their children must be established (Lambert et al., 2008). This is particularly important given the potential disagreements between youth and their parents regarding treatment decisions. In a survey with 258 family medical students at the University of British Columbia, investigators found that conflict resolution and dealing with significant others, including parents, were two of the most challenging problems for SDM (Godolphin, Towle, \& McKendry, 2001a, 2001b). Parents and youth may differ in their perceptions of involvement in the decision-making process. In a survey of 56 caregiver-child groups managing asthma conditions, discrepancies were found between the youth and their caregivers in the perceived involvement of the youth in managing their daily medication decisions. Generally, caregivers overestimated youth involvement (Greenley, Josie, \& Drotar, 2006). Because of potential conflicts between parents and youth regarding medical decisions, the roles of parents should be clearly defined and a formal framework established to engage the participation and consultation of parents and caregivers (Cleary, Freeman, \& Walter, 2006). Alderson et al. (2006) stressed that decisions about treatment should involve a process "to nurture and enlarge children's understanding, trust, and confidence, through the sharing and transferring of insights and responsibilities between adults and children" (p. 33).

Consent and confidentiality. Laws governing minor consent to treatment will inform the definition of roles for youth and parents in SDM. Consent and confidentiality issues can make navigating treatment decisions with youth and their families a complex process. This is particularly true for adolescents, who face the unique circumstance of having advanced cognitive development but not adult legal status. Harrison and Hunt (1999) discussed tension between the law-which in many states does not allow individuals to make treatment decisions until they are 18-and the timing of cognitive development, which is generally fully realized at 15 . While teens are still navigating tasks and activities of adolescence, they will soon be adults who can make their own decisions about medication (Costello, 2003).

Existing mental health laws in most states give parents the authority to give or withhold consent for their child's mental health treatment, although recent statutory and case law on minors' rights and medical emancipation processes have imposed limitations (Costello,
2003). However, in Ohio Northern University Law Review, Costello asserted that children's competence or right to consent to mental health medication treatment is an unsettled area of law. Costello argued that laws should help youth obtain evaluations, treatment, and services that are in their best interest, regardless of parental consent. However, Costello also stated that such laws should not exacerbate conflict between parents and teens and should involve parents when possible. Caution should be taken not to exclude adolescents from decision making simply because they do not agree with the treatment plan. As Harrison and Hunt (1999) have stated, "When an adolescent chooses to inform medical providers that he or she objects to the prescribed treatment plan, his or her view may solidify doubts regarding the adolescents' competence" (p. 6).

Regardless of provisions for the age of consent for mental health treatment, parental involvement is required at some level in most states (Campbell, 2006). Even if this involvement is limited to the parents' right to be informed of treatment decisions, this can complicate confidentiality and privacy issues for adolescents. Even so, confidential health care for adolescents should allow for communication between adolescents and their parents and participation of parents in the health care of their adolescents (Ford, English, \& Sigman, 2004).

SDM for youth requires a balance between establishing rapport with youth by protecting their confidentiality and building an alliance with parents (Huffine, 2005). Seeking a minor's assent during treatment may provide this balance. Assent is a method for involving minors in treatment decisions by sharing information with them about their condition and expectations for treatment. Assent respects a minor's role in treatment decisions and gradually increases their level of autonomy in the process over time. This approach promotes "developmentally appropriate participation in shared decision making with parents and physicians" (Kuther, 2003, p. 351).

System delivery factors. The length of time for appointments, insurance considerations, and the appropriateness of the process are additional service delivery factors that should be examined. Evidence from studies and feedback from practitioners and clients indicate that allowing more time for information sharing, collaboration, and discussion between practitioners and clients would be helpful or even necessary (Edwards \& Elwyn, 2006; Fraenkel \& McGraw, 2007a; Goscha, 2009; Perlman \& Dougherty, n.d.; Towle \& Godolphin, 1999; Towle et al., 2006). However, in a study involving 405 adults with newly diagnosed depression, despite statistically significant improvement in patient participation, no difference in consultation time was found between clients participating in a SDM approach and a nonSDM control group. The latter results suggest that usual appointment times do not necessarily need to be changed (Loh et al., 2007). Consideration should also be given to the impact of shared decisions on health insurance coverage and the cost of services, particularly when clients choose alternative or noncovered treatment options (Wills \& Holmes-Rovner, 2006). Finally, there are some situations where SDM may not be appropriate. These include emergency situations, simple procedures, or situations where temporary incapacity for decision making has occurred (Deegan \& Drake, 2006; Towle et al.).

Identifying outcomes. Identifying outcome measures for the successful implementation of SDM should be an early consideration. There is still significant debate about what the primary aims of SDM should be (Coulter, 2005); thus, appropriate outcomes can vary by individual settings (Fischer, 2006). Examples of outcomes to evaluate the SDM process include measures of the level of client involvement, length of consultation time, increased client knowledge of their con- 
dition and treatment options, and client satisfaction with the process (Coulter; Loh et al., 2007; O’Connor et al., 2003). Health, clinical outcomes, and reduction of symptoms have also been used to assess SDM (Coulter; Loh et al.). Given the patient- or client-focused nature of SDM, it is also necessary to find a balance between outcomes based on a client's individual needs and standardized outcomes based on an organization's expectations. For example, should the utility of a SDM process be based solely on symptom reduction and improved medication adherence? Or should we instead ask, will the use of an SDM framework support subjective outcomes of client-rated satisfaction and well-being? Outcomes used in general medical settings may or may not be relevant to the application of SDM in mental health care, and challenges specific to the mental health service should be examined during both implementation planning and outcome identification (Fischer).

\section{Discussion}

Today, active youth and family participation is a hallmark of evidence-based practice for behavioral health and is equated with competent practice in the United States (Institute of Medicine, 2001; SAMHSA, 2008; Winters \& Pumariga, 2007). For example, Standard 5 of the Standards for the Practice of Social Work with Adolescents calls for "encouraging youths and their families to be active participants in their case planning and service delivery" (National Association of Social Workers, 2003). However, putting these directives into practice requires attention to concrete issues and not just belief in a philosophy of patient-provider collaboration. Education about the value of SDM and garnering patient, provider, and organizational buy-in is essential. This paves the way for addressing SDM practicalities such as role definition, consent and confidentiality, and deciding on suitable outcomes. Interwoven through all of these tasks is the variation in youth developmental levels and youth and parent preferences for involvement.

There also remain concerns from some mental health practitioners about client capacity to participate in decisions, and a perception among some practitioners that the ultimate responsibility for treatment should remain under their authority (Schauer et al., 2007). These challenges may persist despite evidence that individuals diagnosed with a mental illness demonstrate levels of the capacity for decision making similar to those of individuals not diagnosed with a mental illness (Wong, Clare, Holland, Watson, \& Gunn, 2000). This stigma toward mental illness is posited as one of the primary barriers to the full inclusion of youth and family perspective in mental health treatment (Gyamfi, Keens-Douglas, \& Medin, 2007; Hinshaw, 2005; U.S. Department of Health and Human Services, 2000, 2003). With youth, this is compounded by the stigma experienced by family members and caregivers, who are often seen as responsible and to blame for their child's diagnosis (Corrigan, Watson, \& Miller, 2006; Hinshaw). Overall, public stigma and self-stigma serve to discredit youth perspective and derail opportunities for youth-driven and family-guided treatment and ultimately for improving functional outcomes. Schauer et al. (2007) cautioned against the potential for mental health care providers to "undermine and/or severely limit their [patients'] individual potential for growth and reaching beyond limited expectations for employment, education and/or housing opportunities by citing the possibility of stress, relapse and generally negative outcomes rather than promoting growth and shared decision-making" (p. 58).

\section{Implications for Practice}

Integrating SDM into youth mental health practices holds great promise. Evidence suggests that participation in treatment decisions can prepare youth for making their own decisions as adults, can be therapeutic, and can have positive effects on their self-confidence and self-esteem (Butz et al., 2007; Costello, 2003; Tates et al., 2002). However, more research is needed in order to adequately design a SDM model for youth mental health medication treatment. Specifically, formal investigation is needed to identify necessary accommodations for culturally, sociodemographically, and developmentally appropriate youth involvement and the inclusion of parents in mental health treatment decisions (Hetrick, Simmons, \& Merry, 2008; Pescosolido, 2007; Sleath et al., 2010). Principles of adult recovery-oriented mental health services, such as a focus on hope (Friesen, 2007) or the concept of personal medicine or nonpharmaceutical supports (Deegan, 2005), should also be explored as potential supports for adolescents and families. Collecting input and data from practitioners, youth, and parents is critical to developing a process that will work for a range of stakeholders involved in youth mental health SDM (Baston, 2008).

\section{References}

Adams, J. R., \& Drake, R. E. (2006). Shared decision-making and evidence-based practice. Community Mental Health Journal, 42(1), 87-105.

Alderson, P., Sutcliffe, K., \& Curtis, K. (2006). Children's competence to consent to medical treatment. Hastings Center Report, 36(6), 25-34.

Baston, J. (2008). Healthcare decisions: A review of children's involvement. Paediatric Nursing, 20(3), 24-26.

Butz, A. M., Walker, J. M., Pulsifer, M., \& Winkelstein, M. (2007). Shared decision making in school age children with asthma. Pediatric Nursing, 33(2), 111-116.

Campbell, A. T. (2006). Consent, competence, and confidentiality related to psychiatric conditions in adolescent medicine practice. Adolescent Medicine Clinics, 17(1), 25-47.

Cassileth, B. R., Zupkis, R. V., Sutton-Smith, K., \& March, V. (1980). Information and participation preferences among cancer patients. Annals of Internal Medicine, 92(6), 832-836.

Charles, C., Gafni, A., \& Whelan, T. (1997). Shared decision-making in the medical encounter: What does it mean? (Or it takes at least two to tango). Social Science \& Medicine, 44(5), 681-692.

Charles, C., Whelan, T., Gafni, A., Willan, A., \& Farrell, S. (2003). Shared treatment decision making: What does it mean to physicians? Journal of Clinical Oncology, 21(5), 932-936.

Cleary, M., Freeman, A., \& Walter, G. (2006). Carer participation in mental health service delivery. International Journal of Mental Health Nursing, 15(3), 189-194.

Cooper, S., Rimm, M. L., \& Arensdorf, A. M. (2007). Talking about psychiatric medications: A parent-to-parent perspective (for children and youth), part I. Hawaii Medical Journal, 66(10), 260, 262-264.

Corrigan, P. W., Watson, A. C., \& Miller, F. E. (2006). Blame, shame, and contamination: The impact of mental illness and drug dependence stigma on family members. Journal of Family Psychology, 20(2), 239-246.

Corser, W., Holmes-Rovner, M., Lein, C., \& Gossain, V. (2007). A shared decisionmaking primary care intervention for Type 2 diabetes. Diabetes Educator, 33(4), 700-708.

Costello, J. C. (2003). “The trouble is they're growing, the trouble is they're grown": Therapeutic jurisprudence and adolescents' participation in mental health care decisions. Ohio Northern University Law Review, 29(3), 607-640.

Coulter, A. (2005). Shared decision-making: The debate continues. Health Expectations, 8(2), 95-96.

Coyne, I. (2006). Consultation with children in hospital: Children, parents' and nurses' perspectives. Journal of Clinical Nursing, 15(1), 61-71.

Deber, R. B., Kraetschmer, N., Urowitz, S., \& Sharpe, N. (2007). Do people want to be autonomous patients? Preferred roles in treatment decision-making in several patient populations. Health Expectations, 10(3), 248-258.

Deegan, P. E. (2005). The importance of personal medicine: A qualitative study of resilience in people with psychiatric disabilities. Scandinavian Journal of Public Health, 33(Supp. 66), 29-35.

Deegan, P. E., \& Drake, R. E. (2006). Shared decision making and medication management in the recovery process. Psychiatric Services, 57(11), 1636-1639. 
Deegan, P. E., Rapp, C., Holter, M., \& Riefer, M. (2008). Best practices: A program to support shared decision making in an outpatient psychiatric medication clinic. Psychiatric Services, 59(6), 603-605.

Dixon-Woods, M., Young, B., \& Heney, D. (1999). Partnerships with children. BMJ, 319(7212), 778-780

Dogra, N. (2005). What do children and young people want from mental health services? Current Opinion in Psychiatry, 18(4), 370-373.

dosReis, S., \& Myers, M. A. (2008). Parental attitudes and involvement in psychopharmacological treatment for ADHD: A conceptual model. International Review of Psychiatry, 20(2), 135-141.

Edwards, A., \& Elwyn, G. (2006). Inside the black box of shared decision making: Distinguishing between the process of involvement and who makes the decision. Health Expectations, 9(4), 307-320.

Edwards, A., Thomas, R., Williams, R., Ellner, A. L., Brown, P., \& Elwyn, G. (2006) Presenting risk information to people with diabetes: Evaluating effects and preferences for different formats by a Web-based randomised controlled trial. Patient Education and Counseling, 63(3), 336-349.

Elwyn, G., Edwards, A., Kinnersley, P., \& Grol, R. (2000). Shared decision making and the concept of equipoise: The competences of involving patients in healthcare choices. British Journal of General Practice, 50(460), 892-899.

Epstein, R. M., Alper, B. S., \& Quill, T. E. (2004). Communicating evidence for participatory decision making. JAMA, 291(19), 2359-2366.

Fischer, E. P. (2006). Shared decision-making and evidence-based practice: A commentary. Community Mental Health Journal, 42(1), 107-111.

Ford, C., English, A., \& Sigman, G. (2004). Confidential health care for adolescents: Position paper for the Society for Adolescent Medicine. Journal of Adolescent Health, 35(2), 160-167.

Ford, S., Schofield, T., \& Hope, T. (2006). Observing decision-making in the general practice consultation: Who makes which decisions? Health Expectations, 9(2), 130-137.

Fraenkel, L., \& McGraw, S. (2007a). Participation in medical decision making: The patients' perspective. Medical Decision Making, 27(5), 533-538.

Fraenkel, L., \& McGraw, S. (2007b). What are the essential elements to enable patient participation in medical decision making? Journal of General Internal Medicine, 22(5), 614-619.

Friesen, B. J. (2005). The concept of recovery: "Value-added" for the children's mental health field? [Newsletter]. Focal Point: Research Policy and Practice in Children's Mental Health, Resilience and Recovery, 19(1), 5-8.

Friesen, B. J. (2007). Recovery and resilience in children's mental health: Views from the field. Psychiatric Rehabilitation Journal, 31(1), 38-48.

Godolphin, W., Towle, A., \& McKendry, R. (2001a). Challenges in family practice related to informed and shared decision-making: A survey of preceptors of medical students. Canadian Medical Association Journal, 165(4), 434-435.

Godolphin, W., Towle, A., \& McKendry, R. (2001b). Evaluation of the quality of patient information to support informed shared decision-making. Health Expectations, 4(4), 235-242.

Goscha, R. (2009). Finding common ground: Exploring the experiences of client involvement in medication decisions using a shared decision making model (Unpublished doctoral dissertation). University of Kansas, Lawrence.

Greenley, R. N., Josie, K. L., \& Drotar, D. (2006). Perceived involvement in condition management among inner-city youth with asthma and their primary caregivers. Journal of Asthma, 43(9), 687-693.

Grobman, K. H. (2008). Diana Baumrind's (1966) Prototypical Descriptions of 3 Parenting Styles. Retrieved Nov. 19, 2008, from http://www.devpsy.org/ teaching/parent/baumrind_styles.html

Gyamfi, P., Keens-Douglas, A., \& Medin, E. (2007). Youth and youth coordinators' perspectives on youth involvement in systems of care. Journal of Behavioral Health Services \& Research, 34(4), 382-394.

Harrison, L., \& Hunt, B. (1999). Adolescent involvement in the medical decision making process. Journal of Applied Rehabilitation Counseling, 30(4), 3-9.

Hetrick, S., Simmons, M., \& Merry, S. (2008). SSRIs and depression in children and adolescents: The imperative for shared decision-making. Australasian Psychiatry, 16(5), 354-358.

Hinshaw, S. P. (2005). The stigmatization of mental illness in children and parents: Developmental issues, family concerns, and research needs. Journal of Child Psychology and Psychiatry, 46(7), 714-734.

Huffine, C. (2005). Supporting recovery for older children and adolescents. [Newsletter]. Focal Point: Research Policy and Practice in Children's Mental Health, Resilience and Recovery, 19(1), 22-24.

Institute of Medicine. (2001). Crossing the quality chasm: A new health system for the 21st century. Washington DC: National Academy Press.

Karnieli-Miller, O., \& Eisikovits, Z. (2009). Physician as partner or salesman? Shared decision-making in real-time encounters. Social Science \& Medicine, 69(1), 1-8.
Kelsey, J., Abelson-Mitchell, N., \& Skirton, H. (2007). Perceptions of young people about decision making in the acute healthcare environment. Paediatric Nursing, 19(6), 14-18

Kuther, T. L. (2003). Medical decision-making and minors: Issues of consent and assent. Adolescence, 38(150), 343-358.

Lambert, L., Friedman, E., Jerz, M., \& Hacker, K. (2008). Medications and choices: The perspectives of family and youth. What parents and children tell us about psychiatric medications. Cambridge, MA: Institute for Community Health.

Levinson, W., Kao, A., Kuby, A., \& Thisted, R. A. (2005). Not all patients want to participate in decision making. A national study of public preferences. Journal of General Internal Medicine, 20(6), 531-535.

Loh, A., Simon, D., Wills, C. E., Kriston, L., Niebling, W., \& Harter, M. (2007). The effects of a shared decision-making intervention in primary care of depression: A cluster-randomized controlled trial. Patient Education and Counseling, 67(3), 324-332.

Materese, M., McGinnis, L., \& Mora, M. (2005). Youth involvement in systems of care: A guide to empowerment. Reflections from the field. Washington, DC: Technical Assistance Partnership Publication.

McCabe, M. A. (1996). Involving children and adolescents in medical decision making: Developmental and clinical considerations. Journal of Pediatric Psychology, 21(4), 505-516.

Mechanic, D. (1999). Mental health and social policy: The emergence of managed care. Boston: Allyn \& Bacon.

Murray-Swank, A., Dixon, L. B., \& Stewart, B. (2007). Practical interview strategies for building an alliance with the families of patients who have severe mental illness. Psychiatric Clinics of North America, 30(2), 167-180.

National Association of Social Workers. (2003). NASW standards for the practice of social work with adolescents. Washington, DC: Author.

O’Connor, A. M., Stacey, D., Entwistle, V., Llewellyn-Thomas, H., Rovner, D., Holmes-Rovner, M., et al. (2003). Decision aids for people facing health treatment or screening decisions. Cochrane Database of Systematic Reviews, (2), CD001431.

Osher, D., Quinn, M., \& Hanley, T. (2002). Children and youth with serious emotional disturbance: A national agenda for success. Journal of Child and Family Studies, 11(1), 1-11.

Osher, T., Koyanagi, C., Pires, S., McCarthy, J., \& Webman, D. (1997). Child and family focus. Working together to develop integrated systems of care. Behavioral Healthcare Tomorrow, 6(5), CFF1-8 following 40.

Osher, T. W. (1998). Outcomes and accountability from a family perspective. Journal of Behavioral Health Services and Research, 25(2), 230-232.

Osher, T. W., \& Osher, D. M. (2002). The paradigm shift to true collaboration with families. Journal of Child and Family Studies, 11(1), 47-60.

Perlman, S. B., \& Dougherty, R. H. (n.d.). Shared decisions and self-direction as tools for recovery. Behavioral Healthcare. Retrieved July 26, 2008, from http:// www.behavioral.net $/ \mathrm{ME} /$ dirmod.asp? sid $=\& \mathrm{~nm}=$ \&type $=$ Publishing\&mod $=\mathrm{P}$ ublications\%3A\%3AArticle\&mid=64D490AC6A7D4FE1AEB453627F1A4A32 \&tier $=4 \&$ id $=$ DF7A2CE0C28048EE8F0781906447BF89

Pescosolido, B. A. (2007). Culture, children, and mental health treatment: Special section on the National Stigma Study-Children. Psychiatric Services, 58(5), 611-612.

Pescosolido, B. A., Jensen, P. S., Martin, J. K., Perry, B. L., Olafsdottir, S., \& Fettes, D. (2008). Public knowledge and assessment of child mental health problems: Findings from the National Stigma Study-Children. Journal of the American Academy of Child and Adolescent Psychiatry, 47(3), 339-349.

Rosen, P., Anell, A., \& Hjortsberg, C. (2001). Patient views on choice and participation in primary health care. Health Policy, 55(2), 121-128.

Runeson, I., Martenson, E., \& Enskar, K. (2007). Children's knowledge and degree of participation in decision making when undergoing a clinical diagnostic procedure. Pediatric Nursing, 33(6), 505-511.

Substance Abuse and Mental Health Services Administration. (2008). Transforming children's mental health care in America. Retrieved July 26, 2008, from http:// store.samhsa.gov/product/SMA05-4060

Schauer, C., Everett, A., del Vecchio, P., \& Anderson, L. (2007). Promoting the value and practice of shared decision-making in mental health care. Psychiatric Rehabilitation Journal, 31(1), 54-61.

Seale, C., Chaplin, R., Lelliott, P., \& Quirk, A. (2006). Sharing decisions in consultations involving anti-psychotic medication: A qualitative study of psychiatrists' experiences. Social Science \& Medicine, 62(11), 2861-2873.

Sevdalis, N., \& Harvey, N. (2006). Predicting preferences: A neglected aspect of shared decision-making. Health Expectations, 9(3), 245-251.

Sleath, B., Domino, M. E., Wiley-Exley, E., Martin, B., Richards, S., \& Carey, T. (2010). Antidepressant and antipsychotic use and adherence among Medicaid youths: Differences by race. Community Mental Health Journal, 46(3), 265-272. 
Smetana, J. G. (1995). Parenting styles and conceptions of parental authority during adolescence. Child Development, 66(2), 299-316.

Stacey, D., Menard, P., Gaboury, I., Jacobsen, M., Sharif, F., Ritchie, L., et al. (2008). Decision-making needs of patients with depression: A descriptive study. Journal of Psychiatric and Mental Health Nursing, 15(4), 287-295.

Stiggelbout, A. M., \& Kiebert, G. M. (1997). A role for the sick role. Patient preferences regarding information and participation in clinical decisionmaking. Canadian Medical Association Journal, 157(4), 383-389.

Tates, K., Meeuwesen, L., Elbers, E., \& Bensing, J. (2002). "I've come for his throat": Roles and identities in doctor-parent-child communication. Child: Care, Health and Development, 28(1), 109-116.

Thornton, H., Edwards, A., \& Elwyn, G. (2003). Evolving the multiple roles of "patients" in health-care research: Reflections after involvement in a trial of shared decision-making. Health Expectations, 6(3), 189-197.

Towle, A., \& Godolphin, W. (1999). Framework for teaching and learning informed shared decision making. BMJ, 319(7212), 766-771.

Towle, A., Godolphin, W., Grams, G., \& Lamarre, A. (2006). Putting informed and shared decision making into practice. Health Expectations, 9(4), 321-332.

U.S. Department of Health and Human Services. (2000). Report of the Surgeon General's Conference on Children's Mental Health: A national action agenda. Washington, DC: Author.

U.S. Department of Health and Human Services. (2003). Achieving the promise: Transforming mental health care in America (Final report). The President's New Freedom Commission on Mental Health. Retrieved from http://www. mentalhealthcommission.gov/reports/FinalReport/FullReport-02.htm

Volk, R. J., Cass, A. R., \& Spann, S. J. (1999). A randomized controlled trial of shared decision making for prostate cancer screening. Archives of Family Medicine, 8(4), 333-340.
Williams, L., Jones, W., Elwyn, G., \& Edwards, A. (2008). Interactive patient decision aids for women facing genetic testing for familial breast cancer: A systematic Web and literature review. Journal of Evaluation in Clinical Practice, 14(1), 70-74.

Wills, C. E., \& Holmes-Rovner, M. (2006). Integrating decision making and mental health interventions research: Research directions. Clinical Psychology, 13(1), 9-25.

Winters, N. C., \& Pumariga, A. (2007). Practice parameter on child and adolescent mental health care in community systems of care. Journal of the American Academy of Child and Adolescent Psychiatry, 46(2), 284-299.

Wong, J. G., Clare, C. H., Holland, A. J., Watson, P. C., \& Gunn, M. (2000). The capacity of people with a "mental disability" to make a health care decision. Psychological Medicine, 30(2), 295-306.

Young, B., Moffett, J. K., Jackson, D., \& McNulty, A. (2006). Decision-making in community-based paediatric physiotherapy: A qualitative study of children, parents and practitioners. Health \& Social Care in the Community, 14(2), $116-124$.

Megan S. O'Brien, PhD, MPH, research associate; Elizabeth L. Crickard, MA, project manager; Charles A. Rapp, PhD, professor; Cheryl L. Holmes, MPA, project manager; and Thomas P. McDonald, PhD, professor, School of Social Welfare, University of Kansas. Correspondence: mobrie10@ku.edu; School of Social Welfare, University of Kansas, 1545 Lilac Lane, Lawrence, KS 66044-3184.

Manuscript received: February 10, 2010

Revised: June 3, 2010

Accepted: June 3, 2010

\section{Family Resilience in Child Welfare Strengths That Support Successful Reunification}

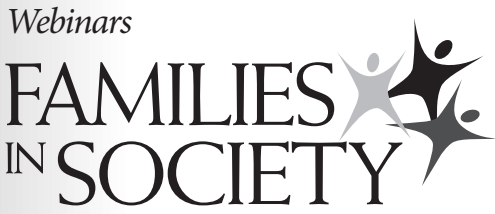

\section{Sept. 6, 2011, 12:00pm-1:30pm (Central)}

Findings from a research study of families whose children were removed due to risk of maltreatment serve as the foundation for this webinar on family resilience in the context of child welfare. A purposive sample of families who successfully navigated difficult circumstances, completed their case plans, and successfully achieved and maintained family reunification were included in the study. Presenter Cynthia A. Lietz, PhD, LCSW, Arizona State University, will highlight implications for practice.

\section{Learning Objectives for Attendees}

- define the construct of family resilience

- describe a typology of family resilience including 5 phases and 10 strengths families suggest are important to healthy coping and adaptation

- understand how the findings support specific applications of strengths-based practice within child welfare

- understand how to apply the findings within practice with high-risk families 